\title{
Mesalazine induced exacerbation of ulcerative colitis
}

\author{
K C Kapur, G T Williams, M C Allison
}

\begin{abstract}
5-Aminosalicylic acid (5-ASA) compounds occasionally exacerbate diarrhoea in patients with inflammatory bowel disease. This is thought to be due to a secretory mechanism in most cases. A patient with presumed intolerance to sulphasalazine and 5-ASA preparations who developed endoscopic and histological evidence of disease relapse after a rectal challenge with mesalazine is reported.

(Gut 1995; 37: 838-839)
\end{abstract}

Keywords: ulcerative colitis, mesalazine, 5-aminosalicylic acid.

Sulphasalazine and other 5-aminosalicylic acid (5-ASA) compounds are extensively used in the management of ulcerative colitis. There are several reports of exacerbations of diarrhoea because of sulphasalazine ${ }^{1-3}$ and 5-ASA compounds. ${ }^{4-7}$ The mechanism of the diarrhoea in most cases is thought to be reduced small intestinal salt and water absorption. ${ }^{8-10}$ True exacerbations of colitis with sulphasalazine have been well documented, ${ }^{12}$ and confirmed on rectal challenge in one patient. ${ }^{3}$ This paradoxical effect of sulphasalazine has been attributed to the sulphapyridine moiety. Ulcerative colitis can also sometimes be exacerbated by non-steroidal anti-inflammatory drugs, and these agents occasionally cause acute colitis in a previously normal colon..$^{1-13}$ We can find only one well documented report of a patient with ulcerative colitis where bloodstained diarrhoea was precipitated by a 5-ASA compound alone, ${ }^{6}$ and now describe a patient where rectal challenge precipitated an immediate disease relapse.

\section{Case report}

A previously fit 30 year old man presented with diarrhoea and rectal bleeding in 1983. This episode responded to sulphasalazine which was stopped by the patient on remission of symptoms. The drug was recommenced for an exacerbation the following year but aggravated diarrhoea and bleeding. Sigmoidoscopy showed oedematous mucosa with contact bleeding and rectal biopsy specimens were consistent with ulcerative colitis. A barium enema was reported as normal. He responded to treatment with oral and rectal corticosteroids but was lost to follow up for eight years.

A further relapse was treated with oral and rectal corticosteroids in 1992 and the patient was discharged on Eudragit ' $S$ ' coated mesalazine (Asacol) which he could not tolerate. He was subsequently given slow release mesalazine (Pentasa) followed by a new Eudragit 'L' coated 5-ASA preparation (Salofalk) but each seemed to exacerbate his diarrhoea and bleeding. He responded subsequently to corticosteroids on each occasion.

\section{5-ASA CHALLENGE}

By February 1994 the patient had been asymptomatic on no treatment for four months. It was considered important for his future management to confirm objectively the nature of his intolerance to 5-ASA compounds. We therefore decided to give him a rectal challenge with mesalazine. Flexible sigmoidoscopy undertaken before the challenge showed loss of vascular pattern and mild erythema only. Biopsy specimens were taken from the descending colon, mid sigmoid colon, and the rectum. After informed consent, he received a single mesalazine suppository $(250 \mathrm{mg})$, and he developed bloodstained diarrhoea four hours later. Repeat flexible sigmoidoscopy the following week showed confluent disease activity at least up to the descending colon, with granular mucosa and contact haemorrhage. Biopsy specimens were taken from the same three sites for comparison with the prechallenge samples.

\section{HISTOLOGY}

All pre-challenge biopsy specimens showed features of chronic ulcerative colitis in remission, with an increase in chronic inflammatory cells in the lamina propria and distortion of the crypt architecture, but no evidence of neutrophil polymorph infiltration or appreciable mucus depletion.

All three specimens taken after challenge showed active inflammation with a diffuse infiltrate of neutrophil polymorphs in the lamina propria that extended into the crypt epithelium, especially in the basal half of the mucosa where there was also mucus depletion (Figure). No crypt abscesses were seen and there were no granulomas. Neither eosinophil nor epithelial apoptosis were increased in comparison with the pre-challenge specimens. While the histological appearances clearly showed active inflammation in the specimens taken after mesalazine, there were no specific pointers to a drug induced lesion as opposed to a relapse of ulcerative colitis.

\section{Discussion}

Watery diarrhoea occurs in up to $15 \%$ of
Dr M C Allison, Department of Gastroenterology, Royal Gwent

Accepted for publication 11 May 1995 


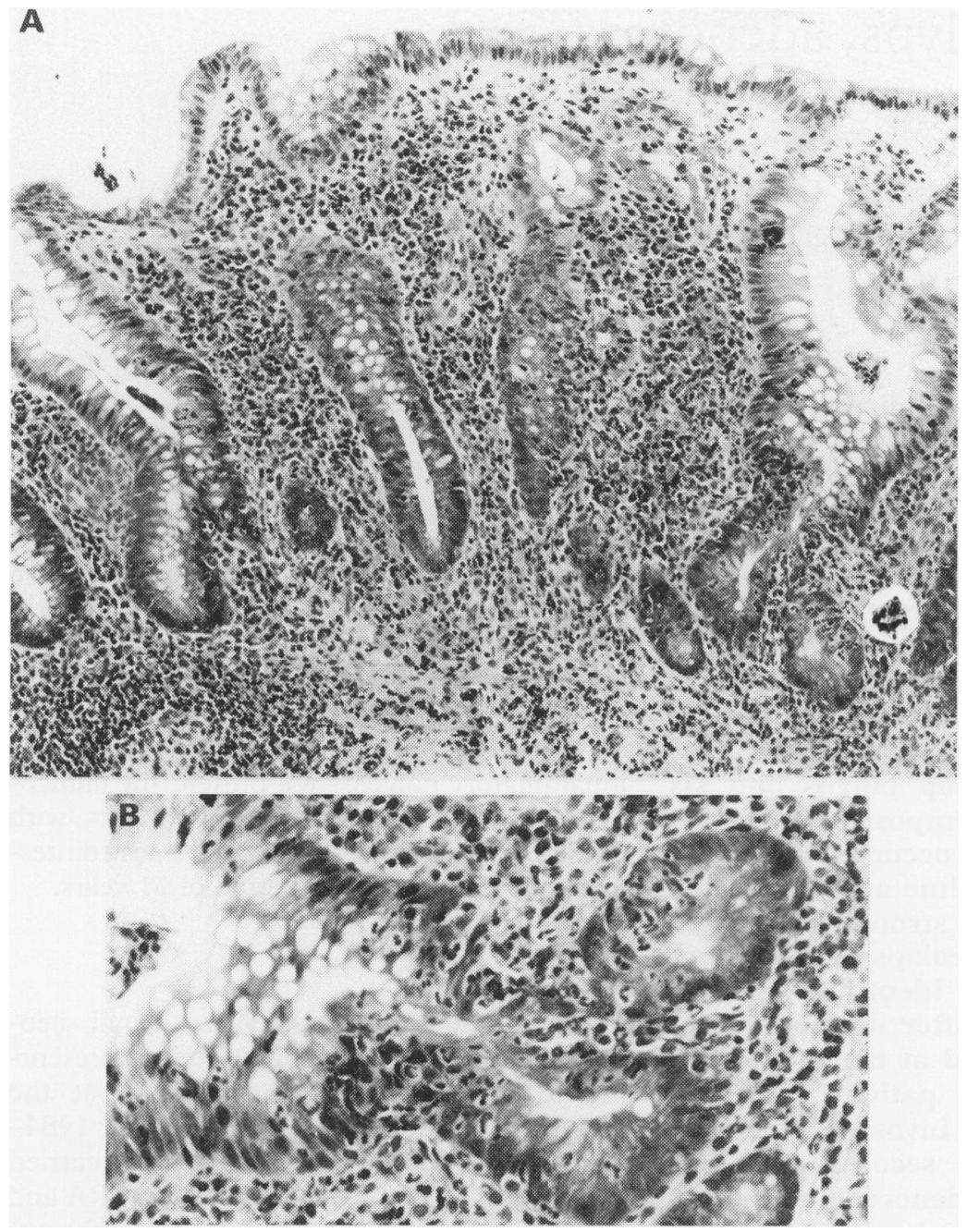

Figure: (A) Histological appearances of sigmoid colon following mesalazine challenge. There is diffuse acute on chronic mucosal inflammation with architectural distortion and goblet cell depletion (haematoxylin and eosin $\times 80$ ). (B) Intracryptal neutrophil polymorphs are present in the basal zone (haematoxylin and eosin $\times 200$ ).

patients given 5-ASA in the form of olsalazine. This side effect is thought to be secondary to the inhibition of ileal and colonic $\mathrm{Na}^{+} \mathrm{K}^{+}$ ATPase ${ }^{8-10}$ which leads to reduced absorption and increased secretion of water thus increasing the fluid load to the colon. ${ }^{9}$ The phenomenon occurs more frequently in patients with extensive rather than with more limited colonic involvement. ${ }^{9} 10$

Most reports of gastrointestinal intolerance to sulphasalazine and 5-ASA compounds describe systemic features including fever, nausea, vomiting, and rashes. Some of these features are considered to be manifestations of an allergic response rather than drug induced disease exacerbations. By contrast, the onset of symptomatic relapse in our patient was accompanied by very little systemic upset. Endoscopic and histologically confirmed relapse was induced by a single suppository of mesalazine and there was no clinical or histological evidence of a specific drug reaction.

We presume that exacerbation of disease in the more proximal colon was due to haematogenous spread of mesalazine absorbed by the rectal mucosa.

Research into the mechanisms of this rare 5-ASA induced paradoxical disease exacerbation may shed light on the more usual remission inducing and relapse preventing properties of these drugs in ulcerative colitis.

1 Werlin S, Grand R. Bloody diarrhoea - a new complication of sulphasalazine. 7 Paediatr 1978; 92: 450-1.

2 Ruppin H, Domschke S. Acute ulcerative colitis - a rare complication of sulphasalazine therapy. Hepatogastrocomplication of sulphasalaz

3 Schwartz A, Targan S, Saxon A, Weinstein W. Sulphasalazine induced exacerbation of ulcerative colitis. New Engl f Med 1982; 306: 409-12.

4 Giaffer M, O'Brien C, Holdsworth CD. Clinical tolerance to three 5-aminosalicylic acid releasing preparations in patients with inflammatory bowel disease intolerant or allergic to sulphasalazine. Aliment Pharmacol Therap 1992; 6: 51-9.

5 Austin AC, Cann PA, Jones TH, Holdsworth CD. Exacerbation of diarrhoea and pain in patients treated with 5-aminosalicylic acid for ulcerative colitis. Lancet 1984; i: $917-8$.

6 Chakravorty TK, Bhatia D, Heading R, Ford M. Salicylate induced exacerbation of ulcerative colitis. Gut 1987; 28: 613-5.

7 Fardy J, Lloyd D, Reynolds R. Adverse effects with oral 5-aminosalicylic acid. f Clin Gastroenterol 1988; 10 (6): 635-7.

8 Madsen R. Functional alterations in ulcerative colitis. In: Robinson JWL. Intestinal ion transport. Lancaster: MTP, 1976: 381-97.

9 Sandberg-Gertzen H, Jarnerot G, Kraaz W. Azodisal sodium in the treatment of ulcerative colitis. sodium in the treatment of

10 Scheurlin C, Allgayer H, Kruis W, Erdmann E, Sauerbruch $T$. Effect of olsalazine and mesalazine on human ileal and colonic $\mathrm{Na}^{+} \mathrm{K}^{+}$ATPase, a possible diarrhogenic factor? Clin Invest 1993; 71 (4): 286-9.

11 Bjarnason I, Hayllar J, Macpherson A, Russell A. Side effects of nonsteroidal anti-inflammatory drugs on the small and large intestine in humans. Gastroenterology 1993; 104: 1832-47.

12 Rampton D, McNeil N, Sarner M. Analgesic ingestion and other factors preceding relapse in ulcerative colitis. Gut 1983; 24: 187-9.

13 Rampton D, Sladen G. Relapse of ulcerative proctocolitis during treatment with non-steroidal anti-inflammatory drugs. Postgrad Med 7 1981; 57: $297-9$.

14 Trunen U, Eloma I, Antilla V, Seppala K. Mesalazine tolerance in patients with inflammatory bowel disease and previous intolerance or allergy to sulphasalazine or sulphonamides. Scand $\mathcal{f}$ Gastroenterol 1987; 22: 332-6. 